\title{
O AMOR: FUNDAMENTO DA EDUCAÇÃO TRANSDISCIPLINAR
}

\author{
AMOR: LA FUNDACIÓN DE LA EDUCACIÓN TRANSDISCIPLINARIO
}

\section{LOVE: FOUNDATION OF THE EDUCATION TRANSDISCIPLINARY}

VIANA, Rosa Maria ${ }^{1}$

OLIVEIRA, Sandra de Fátima de ${ }^{2}$

\begin{abstract}
"Falem sobre o amor, pois o amor é a verdadeira base da vida. Sem amor não haveria vida"
\end{abstract}

Sai Baba

\begin{abstract}
RESUMO: Este artigo tem o intuito de apresentar os fundamentos da abordagem teórica Transdisciplinar que deram base para consolidar um Núcleo de Estudos na Área Ambiental e transdisciplinaridade em Goiânia: O NUPEAT - Núcleo de Pesquisa e Estudos em Educação Ambiental e Transdisciplinaridade, constituído em 2006. Sediado no Instituto de Estudos Sócio Ambientais-IESA, no Campus II da Universidade Federal de Goiás-UFG, Brasil, o NUPEAT é formado por professores e estudantes da Graduação e Pós - graduação de diferentes Unidades acadêmicas da UFG, e parceira da Universidade Salgado Oliveira através de Seu Programa Institucional "UNIVERSO da Paz". Atuando nas áreas temáticas de Educação Ambiental e da Transdisciplinaridade, o NUPEAT tem como objetivo promover estudos e pesquisas que integrem diversas disciplinas e áreas do saber, bem como o conhecimento popular, para lidar com temas que estejam entre, através e além das disciplinas, sobretudo o ambiental. Estimula diálogos Transdisciplinares e contribui para a solução de problemas abrangentes que afetam a sociedade, e difunde a Cultura de PAZ.
\end{abstract}

Palavras chave: transdisciplinaridade, educação ambiental, pesquisa, teoria, cultura de paz.

RESUMEN: Este artículo tiene como objetivo proporcionar las bases del enfoque teórico que se basa Transdisciplinario para consolidar un Centro de Área de Estudios del Medio Ambiente y la transdisciplinariedad en Goiânia: El NUPEAT - Centro de Estudios e Investigación en Educación Ambiental y transdisciplinariedad, establecida en 2006. Con base en el Instituto de Investigaciones Socio-Ambiental IESA, Campus II de la Universidad Federal de Goiás-UFG,

\footnotetext{
${ }^{1}$ Rosa Maria Viana é Doutora em Ciências Sociais / IFCH-UNICAMP. Docente e Pesquisadora da Universidade Salgado Oliveira onde coordena o Programa UNIVERSO da Paz e Sustentabilidade da Vida. rosamvianapaz@gmail.com

${ }^{2}$ Sandra de Fátima de Oliveira é Doutora em Ciências pela USP, e Mestre em Geociências . Docente e Pesquisadora no Instituto de Estudos Sócio-Ambientais da UFG, onde Coordena o Núcleo de Pesquisa e Estudos em Educação Ambiental e Transdisciplinaridade- NUPEAT. $\quad \underline{\text { sanfaoli@gmail.com }}$
} 
Brasil, NUPEAT está formado por profesores y estudiantes de Grado y Post - Graduados de las diferentes unidades académicas de la Universidad UFG y socio Salgado Oliveira Programa Institucional a través de su "Universo de la Paz." De las áreas temáticas de la educación ambiental y la transdisciplinariedad, la NUPEAT tiene como objetivo promover estudios e investigaciones que se integran diversas disciplinas y áreas del conocimiento y el saber popular, para tratar las cuestiones que están entre, a través y más allá de las disciplinas, especialmente el medio ambiente. Estimula el diálogo transdisciplinario y contribuye a la solución de problemas que afectan a la sociedad global, y difunde la Cultura de la Paz.

Palabras clave: transdisciplinariedad, la educación ambiental, la investigación, la teoría, la cultura de la paz

ABSTRACT: This article aims to provide the foundations of theoretical approach that based Transdisciplinary to consolidate a Center for Environmental Studies Area and transdisciplinarity in Goiânia: The NUPEAT - Center for Studies and Research in Environmental Education and Transdisciplinarity, established in 2006. Based at the Institute of Socio-Environmental IESA, Campus II, Federal University of Goiás-UFG, Brazil, NUPEAT is formed by professors and students of Graduate and Post - Graduate from different academic units of UFG and partner University Salgado Oliveira Institutional Program through His "Universe of Peace." Acting in the thematic areas of environmental education and Transdisciplinarity, the NUPEAT aims to promote studies and research that integrate various disciplines and areas of knowledge and popular knowledge, to deal with issues that are between, across and beyond disciplines, especially the environment. Transdisciplinary stimulates dialogue and contributes to the solution of problems that affect society comprehensive, and diffuses the Culture of Peace.

Key word: transdisciplinarity, environmental education, research, theory, culture of peace

\section{APRESENTAÇÃO}

Este artigo tem o intuito de apresentar os fundamentos da abordagem teórica Transdisciplinar que deram base para consolidar um Núcleo de Estudos na Área Ambiental em Goiânia: O NUPEAT.

Desde 2002 um grupo de docentes e acadêmicos da UFG e da Universo/Goiânia, sob a liderança da Profa. Sandra de Fátima Oliveira se encontravam no IESA/UFG para trocar idéias sobre novos paradigmas, física quântica, realidade macro e microfísica e, em especial, o compromisso ético com a vida, tendo por base os Valores Humanos Universais. Destes encontros nasceu a idéia do o Núcleo de Pesquisa e Estudos em Educação Ambiental e Transdisciplinaridade - NUPEAT, constituído em 2006. 
Sediado no Instituto de Estudos Sócio Ambientais-IESA, no Campus II da Universidade Federal de Goiás, o NUPEAT é formado por professores e estudantes da Graduação e Pós graduação de diferentes unidades acadêmicas da UFG, e parceira da Universidade Salgado Oliveira através de Seu Programa Institucional "UNIVERSO da Paz".

Atuando nas áreas temáticas de Educação Ambiental e da Transdisciplinaridade, o NUPEAT tem como objetivo promover estudos e pesquisas que integrem diversas disciplinas e áreas do saber, bem como o conhecimento popular para lidar com temas que estejam entre, através e além das disciplinas, sobretudo o ambiental. Estimula diálogos Transdisciplinares e contribui para a solução de problemas abrangentes que afetam a sociedade, e difundir a Cultura de PAZ.

Dessa forma, a constituição do NUPEAT visou atender, também, o apelo da Organização das Nações Unidas - ONU para ampliar a compreensão entre as pessoas e países promovendo a Cultura de Paz, definida pela resolução 53/243 de 06/10/99 em seu Artigo $1^{o}$ :

"Uma Cultura de Paz é um conjunto de valores, atitudes, tradições, comportamentos e estilos de vida baseados no respeito à vida, no fim da violência e na promoção e prática da não-violência por meio da educação, do diálogo e da cooperação.”

Através dessa Declaração sobre a Cultura de Paz, a ONU propõe diretrizes com o objetivo de que Governos, organizações internacionais e sociedade civil possam orientar suas atividades a fim de promover e fortalecer uma Cultura de Paz no mundo todo, nesse no século 21. Mas para fazer da Cultura de Paz uma realidade concreta e duradoura é necessário desenvolver um processo de conscientização, mobilização, educação, formação e informação de todos os níveis sociais em todos os países.

O NUPEAT atendeu esse desafio da ONU para a concretização da Cultura de Paz no Cerrado Brasileiro. Sua proposta incluiu a realização de pesquisas e estudos nas áreas de Educação Ambiental (EA) e Transdisciplinaridade, a promoção de espaços para refletir sobre a transdisciplinaridade e seus pilares: a complexidade, os diferentes níveis de realidade e a lógica ternária ou do terceiro incluído e a Cultura de Paz. Nesses estudos e encontros o NUPEAT abriu espaços para aprofundar os conhecimentos relacionados aos novos paradigmas oriundos dos conhecimentos atuais da física quântica, seus questionamentos sobre a Realidade e seus desdobramentos na vida cotidiana - colocando Base para a Ação Humana consciente e amorosa.

Através da lista de comunicação do NUPEAT seus participantes mantêm um espaço de diálogo permanente, onde trocam informações sobre os mais diversos assuntos voltados para a 
transformação e emancipação humana no cuidado com todos os seres vivos, com a teia da vida, com a MÃE TERRA.

Entre várias atividades desenvolvidas pelo NUPEAT estão o CININUPEAT que apresenta filmes, documentários e vídeos relacionados com a questão ambiental, modos de vida, diversidade, etc; oficinas temáticas ; vivências e sensibilizações; Círculos de Estudos de Valores Humanos e Cultura de Paz; roda de prosa; Cantos , poesias; as feiras de trocas, divulgação da Economia Solidária com reflexões sobre a mudança de indicadores de desenvolvimento através dos encontros para divulgação do FIB - Felicidade Interna Bruta.

Em outubro de 2008 o NUPEAT organizou dois importantes eventos: o I Congresso Goiano de Educação Ambiental e o I Simpósio sobre Educação Ambiental e Transdisciplinaridade dos Povos Cerradeiros .

E agora lança a "Revista Terceiro Incluído" e promove o II SEAT ampliando reflexões e consolidando na comunidade acadêmica um espaço amoroso de dialogo Transdisciplinar que vem atender os anseios de desenvolvimento do SER com base em Valores Humanos - que resgata a essência verdadeira do Humano em Nós: a nossa Capacidade de Amar e de estabelecer relações pacíficas e compassivas com todos os Seres que compartilham a Vida no Seio da Mãe Terra.

\section{INTRODUÇÃO}

O NUPEAT ao adotar a abordagem transdisciplinar como fundamento para a sua atuação, assume o desafio que tem a educação no momento atual - introduzir novas perspectivas que integrem os saberes humanos, promovendo o desenvolvimento social e a formação humana a partir de valores absolutos e princípios éticos, tendo por foco a Vida, e por objetivo propiciar novos caminhos para a transformação do ser humano e da sociedade, para constituir uma vivência de paz. A perspectiva teórica que abarca essas questões se tornou conhecida como "Abordagem Transdisciplinar".

Como fala Basarab Nicolescu em vários textos, a transdisciplinaridade pode ser compreendida como uma proposta teórico-metodológica que tem como objetivo integrar as diferentes áreas do conhecimento e também as várias formas de produzir e vivenciar conhecimentos que a humanidade elaborou no decorrer de seu trajeto. Assim, propõe a interação das várias disciplinas científicas, e indo além delas, busca promover a sua união com 
outras formas de saber, entre elas a Filosofia, as Artes e as Tradições Espirituais, atendendo uma visão complexa do ser humano e sua ação no mundo.

Ao integrar diferentes sistemas de conhecimento, a transdisciplinaridade envolve, e desenvolve, diferentes aspectos do ser humano, integrando pensamento, sentimento, intuição, sensibilidade, cognição, corporeidade, emoção e espiritualidade. O que nos sustenta para o exercício de ser, pensar e fazer sob referenciais de uma práxis educativa que integra a racionalidade e o sentimento, a análise e a vivência, que nos leva a sentir o mundo e nós mesmos como uma única e mesma totalidade.

Esse exercício pleno do sentido de existir compreende o amor como fonte de vida, resgata o sagrado na existência humana e abre o caminho para uma vivência de paz e valores humanos - o que nossa época histórica exige hoje, mais do que nunca - a vivência de princípios éticos e valores na vida pessoal, social e no cuidado com a Terra.

\section{A ESSENCIA HUMANA - O AMOR}

A proposta teórico-metodológica oferecida pela transdisciplinaridade aparece assim como uma resposta a necessidade histórica do nosso tempo, possibilitando a formação humana comprometida com a construção de um mundo melhor, consolidando o princípio que fundamenta as tradições espirituais de todas as culturas: o amor como sustentação da vida. Amor que se expressa pelo outro, por si mesmo e por toda a criação.

Nessa construção, a Educação cumpre um papel fundamental frente às necessidades da nossa época histórica que exige uma formação humana integral, a formação que propicia a vivência de valores e da ética do cuidado planetário. E para tanto se deve desenvolver o potencial superior do Ser Humano: a generosidade, a fraternidade, a solidariedade e o amor, todos presentes em cada pessoa, esperando apenas as condições favoráveis para florescer. Esperando o toque de amor dos educadores.

Nesse nosso tempo histórico atual - terceiro milênio- podemos entender, e atender o alerta que Engels nos fazia sobre os perigos da visão e atitudes de Dominadores que o ser humano assumiam frente a natureza. Apontava Engels o nosso engano - que o domínio que temos sobre a natureza não corresponde ao domínio de

"um conquistador sobre o povo conquistado, que não é o domínio de alguém fora da natureza, mas que nós, por nossa carne, nosso sangue e nosso cérebro, pertencemos à natureza, encontramos-nos em seu seio, e todo o nosso domínio sobre ela consiste em que, diferentemente dos demais seres, somos capazes de conhecer suas leis e aplicá-las de maneira adequada. Com efeito, aprendemos cada dia a compreender melhor as leis da natureza e a conhecer tanto os efeitos imediatos como as conseqüencias remotas de nossa 
intromissão no curso natural de seu desenvolvimento. (...) ( e portanto com condições de prever e controlar os efeitos dos nossos atos na produção). E quanto mais isso seja uma realidade, mais os homens sentirão e compreenderão sua unidade com a natureza, $e$ mais inconcebível será essa idéia absurda e anti natural de antítese entre o espírito e a matéria, o homem e a natureza, a alma e o corpo." (p. 71/72)

Antecipando em um século o conceito de co-criação, pertencimento e unicidade que hoje, no século XXI vem sendo apregoado pelos pensadores da questão ambiental, Engels, em seu trabalho conjunto com Marx "Do socialismo utópico ao socialismo científico”, prever um novo tempo para a humanidade, a verdadeira humanidade, aquela que está baseada na cooperação com a natureza e com os seres humanos.

Esse tempo novo, segundo Engels, se inicia ao cessar a luta pela existência individual $e$ o ser humano sai definitivamente do reino animal e passa a viver em condições de vida verdadeiramente humanas quando

"a própria existência social do homem, que até aqui era enfrentada como imposto pela natureza e a história, é de agora em diante obra livre sua. Os poderes objetivos e estranhos que até aqui vinham imperando na história colocam-se sob o controle do próprio homem. Só a partir de então , ele começa a traçar a sua historia com plena consciência do que faz".

\section{"É o salto da humanidade do reino da necessidade para o reino da liberdade"}

Esse reino da liberdade é o reino no qual podemos expressar verdadeiramente nossa natureza humana, podemos resgatar e viver os valores que propiciam a nossa espécie ser uma, entre várias outras na teia da vida, como nos diz Humberto Maturana em sua "Ontologia da Realidade“ (1997), com uma especificidade - podemos trazer para a vida social a nossa essência humana que se constrói pelo amor.

Esse é o reino da Liberdade, quando podemos expressar nossa essência amorosa para propiciar uma nova etapa na historia da humanidade - a etapa que promove a constituição de uma cidadania planetária pacífica e harmoniosa. Cidadania que se baseia na compreensão de que todos os povos constituem uma única humanidade que compartilha, com todos os seres vivos, um espaço comum - o Planeta Terra.

Estas reflexões são básicas para demonstrar a possibilidade de reconduzirmos nossas ações com diferentes maneiras de atuação, apontando o papel que a reflexão histórica propicia para o aprendizado humano. Reflexão que nos permite tomar consciência dos nossos próprios atos, repensando e transformando o modelo produtivo explorador, a distribuição desigual da 
riqueza produzida através da exploração dos recursos naturais e do trabalho humano, formando uma sociedade justa e harmônica.

Enfim, consolidando os ensinamentos que fundamentam as tradições espirituais de toda a humanidade, de todas as culturas: "o amor que se expressa pelo outro, por si mesmo e por toda a criação".

Para Regina Migliori (1999), o ser humano deve exercer toda a sua competência amorosa para garantir que o conhecimento acumulado pela humanidade possa ser exercido na preservação da vida.

É nesse mesmo sentido também que nos fala Ubiratan D’Ambrosio (1998) ao apontar que o problema maior do conhecimento é entender o indivíduo como uma realidade individual, social, planetária e cósmica que assume uma ética nas suas relações consigo próprio, com o outro, com a natureza e com o cosmo. Segundo o autor esta é a ética da diversidade que propicia:

1. O respeito pelo outro com todas as suas diferenças;

2. Solidariedade com o outro na satisfação de suas necessidades materiais e espirituais, de sobrevivência e de transcendência; e

3. Cooperação com o outro na preservação do patrimônio natural e cultural.

D’Ambrosio define como ético o indivíduo que no seu comportamento incorpora o conhecimento de si próprio de sua inserção na sociedade, de suas responsabilidades planetárias e de suas essencialidades cósmicas.

Para isso, afirmam Hoeffel e Viana (1998), temos que participar da mudança e vivê-la como desafio essencial, colaborando com a construção de uma comunidade harmoniosa apoiada em valores humanos - Verdade, Paz, Ação Correta, Não-violência, Amor - verdadeira essência do ser humano, como base do crescimento pessoal e comunitário. Esse é o nosso grande desafio para tornar nossas relações verdadeiramente humanas nos planos interpessoal, comunitário, planetário e cósmico.

$\mathrm{Na}$ perspectiva transdisciplinar a integração do saber humano produzido pelas várias áreas - ciência, filosofia, artes e tradições sagradas, fundamentadas em valores humanos criam novos caminhos para a transformação do ser humano e da sociedade.

Ao integrar tantas áreas, a transdisciplinaridade integra também o pensamento, o sentimento, a intuição, a cognição e a emoção. E evidencia a sua relação com as propostas educacionais que não se recusam a usar a palavra amor, no amplo sentido como propõem Maturana e o educador indiano Sai Baba. E também respalda as propostas referenciadas nos aportes sociais e políticos, como a de Paulo Freire, que promove o exercício de ser, pensar e 
fazer com base em referenciais de análise e vivência, que nos faz assumir nosso papel histórico na sociedade em que vivemos.

Esse exercício pleno do sentido de existir compreende o amor como fonte de vida, e resgata o sagrado na existência humana. O sagrado não como um atributo de uma única religião, mas no sentido dado por Mircea Eliade: "O sagrado como a experiência de uma realidade e a origem da consciência de existir no mundo."

Sagrado que, no dizer de Maria Cândida Moraes na sua tese sobre o "Paradigma Emergente na Educação", designa o ser humano como "um ser espiritual que vivencia uma jornada individual e coletiva, possui um Sagrado individual em comunicação íntima com o Sagrado coletivo, em comunhão com os outros e com a natureza; uma espiritualidade a ser compreendida como ligação direta do indivíduo com a Fonte, com a Totalidade, com o Cosmo."

A vivência da dimensão espiritual nos remete a todos os estados de consciência e a todas as funções e atividades humanas que têm como denominador comum a posse e o desenvolvimento de valores superiores - éticos, estéticos, humanitários e altruístas,

Uma educação que abra espaço para o desenvolvimento da nossa capacidade de indagar e de procurar respostas para as perguntas fundamentais do ser humano - quem somos nós e porque vivemos? Uma educação que estimule a encontrar as respostas para essas questões com uma profundidade e alcance que venha repercutir na nossa vida cotidiana, na transformação social e planetária, permitindo emergir a vivência da unidade da teia da vida e o estabelecimento de relações que expressam a essência do Amor, que é a própria natureza do ser humano.

É certo que esse paradigma surge quando imperam ainda, as antigas formas de pensar, constituindo uma convivência de modos diferenciados de compreender o mundo colocando para a nossa geração de educadores neste inicio do Século XXI, o desafio e também a responsabilidade de iniciar o exercício de ser, pensar e fazer com base nesses novos referenciais de análise, vendo o mundo e nós mesmos como uma única e mesma totalidade.

Essa visão de totalidade com a terra, se entendida como sistema vivo - Gaia, corresponde uma visão diferenciada do planeta e de ser humano. Gaia constitui-se de ecossistemas que, em rede de interação, compõem um único organismo vivo imenso, sustentando toda a vida na superfície da terra: é Gaia viva, consciente de todas as células de seu corpo natural e social onde nós, seres humanos, somos uma entre os bilhões de espécimes da vida nesse grande sistema vivo. 
A prática educacional que possibilita esta vivência integradora de um mundo relacional, sensível e amoroso deverá promover a reunificação do ser humano e do mundo natural como uma única comunidade sagrada, pois se não for assim, ambos perecerão no caminho da destruição.

A proposta educacional que considera o ser humano integrado ao universo e o conduz a se sentir responsável pelo "seu mover no mundo", propicia experiências que levam o educando a se sentir como elemento dessa unidade de diversidade que é a essência da natureza do mundo.

Como nos apontou Gandhi com sua maneira de fazer história com base nos princípios da não-violência, o que leva a unidade de toda a vida no planeta é nossa ação comprometida com o desafio de "ver o outro como nosso irmão". Em sua visão libertadora e não separatista , Gandhi afirmava que todos os seres vêm de um mesmo Deus/Ser Criador, e nesse caso toda vida, seja qual for a maneira em que se manifesta, só pode ser essencialmente uma.

A compreensão de mundo de Gandhi se expressa também nos princípios da Educação em Valores Humanos, proposta pedagógica aplicada pelo educador indiano Sathya Sai Baba ${ }^{5}$, que afirma a unicidade do Universo. No dizer de Sathya Sai é preciso reconhecer a realidade Única por trás da multiplicidade da forma. Atrás das aparentes diferenças todos são essencialmente Um. A experiência humana é só uma forma de manifestação da Unidade (Atma) que se individualiza no sistema corpo-mente. Assim o ser individual é reflexo, é parte do Universo, da totalidade. E o sentido da Educação é possibilitar a percepção consciente dessa unidade:

“o ser humano é uma parte do todo e o todo é Deus. Na verdade tudo é Deus em diferentes manifestações...

Toda religião nos ensina a amarmos uns aos outros e a lembrar que o Amor é a maior força do Universo.

Deus é o Amor na forma mais elevada e o Ser Humano pode se esforçar para deixar este amor se manifestar em si mesmo, por toda a vida, em todos os momentos (...) o tempo de despertar é agora e todos os pensamentos de diversidade devem ser deixados para trás." (Sai Baba, 2000 : 08)

\footnotetext{
${ }^{5}$ Ver conferências e pronunciamentos do educador indiano Sathya Sai Baba.
} 


\section{O AMOR COMO FUNDAMENTO DA VIDA}

A visão do educador Sathya Sai aponta para uma compreensão de Amor complexa, multidimensional e extremamente diferente do que entendemos por amor como sentimento : Amor é a energia que sustenta o Universo.

É também como energia que sustenta a matéria organizada que o amor é compreendido pelo físico Brian Swng ${ }^{6}$ para quem o amor está em tudo e todos, e cada ser no planeta expressa amor: "O amor é energia. Essa energia é a que nos dá a vida, nos sustenta e nos possibilita a manifestação no sistema corpo-mente. (...) o Amor é a verdadeira base do Universo, sem Amor não haveria Universo”.(Swng 1997:37)

Também para Humberto Maturana (1998), que vem estudando a questão da emoção como componente fundamental da natureza humana, o amor é uma questão da própria biologia da espécie humana, e está na base do comportamento ético. "É só através do amor que o outro tem presença”, pois o convite ético não é racional, mas emocional:

Não digo como o Papa 'O amor é mais forte'. Digo que a biologia é mais forte. O amor não é uma coisa especial, é cotidiano, e vocês notarão que em todas as situações de crise humana, de crise nas comunidades, de terremotos, de incêndios, de situações extremas, as pessoas se encontram num nível básico humano onde a solidariedade está presente e nem sequer é preciso recomendá-la, ela aparece sozinha. Por quê? Porque o amor nos pertence como característica biológica que constituem o humano. (1998:85)

Na Educação em Valores Humanos o amor deve ser desenvolvido desde o início da formação infantil para atender às dimensões do ser humano em suas diversas expressões:

"Amor como Pensamento é Verdade; Amor como Ação é Retidão; Amor como Sentimento é Paz; Amor como Compreensão é Não-Violência".

Trata-se, então, de expandir o ato de compreender, que se reflete na transformação do sentido da palavra estabelecido pelo senso comum, ou pelo registro denotativo dos dicionários. Mais que a designação de um sentimento entre pessoas, o Amor é visto em sua complexidade e nos diferentes modos em que o Ser Humano o vivencia.

${ }^{6}$ Swng, B. O Universo é um Dragão Verde. S. Paulo, Cultrix, 1997. 
Em seu texto o Redespertar Espiritual no Trabalho escrito em 1995, o administrador de empresas, Jacque Hawley aborda essa visão do amor como algo além de sentimento indicando suas variações:

Amor como desejo (amor carente) - a palavra amor é usada indiscriminadamente para designar manifestação do desejo, apego, cobiça, propriedade ou qualquer outra coisa que expressa o querer algo.

Amor como sentimento (amor emocional) - o amor que consiste em sentimentos de amor entre pessoas, afeto, fascínio, atração. É emoção, pensamento e atitudes. A idéia chave é que o Amor é o sentimento de amar, de dedicação, perdão, fraternidade e dignidade.

Amor como ação (amor ativo) - nesse quadro o amor é visto como os atos cotidianos realizados pelos seres vivos envolvendo Seres Humanos e outros seres. Podem ser ações visíveis ou invisíveis, sutis. Amor que se reflete nas ações de gentileza, doação, auxílio, compartilhamento, tolerância, onde os seres humanos não apenas demonstram, mas de fato são os sentimentos vivos, consubstanciados nos atos.

Amor como doação (amor altruísmo) - esse amor conecta as forças mais elevadas superando os laços da identidade pessoal não havendo um "eu" nesse amor. O doador e o receptor se tornam um, sendo o espaço entre os dois preenchidos de uma qualidade nova, profunda, onde o exercício é amar ao próximo como a si mesmo.

Amor como energia (amor potente) - aqui o amor está além de qualquer forma, é pura energia é o lugar da sabedoria, além do conhecimento: onde o amor se estende tocando o mundo e todas as almas que nele existem. Neste plano o amor e vontade correspondem ao poder da intencionalidade. Nada se move no planeta sem ele. É o impulsionador do movimento , é a "ânsia primal profunda, em direção à unidade, ao conhecimento interior de que somos unidos a todos os outros, de que somos todos um só.” (Hawley, 1995 : 98) Esse amor além da forma pertence ao mundo invisível e vibratório, e se manifesta como voz interior.

Amor como espírito (amor existencial) - essa é outra dimensão, muito além da forma visível e do invisível, além do tempo e do espaço, abrangendo o Ser. Para Hawley é dessa dimensão de amor que viemos e de onde o amor emana: " este é o lugar que chamamos de Eu Superior, ou Consciência Superior. Neste lugar espírito e Eu são a mesma coisa”.

Essa dimensão de amor é ainda estranha para a mente humana, principalmente para a mente do ocidental, que é treinada na noção de um mundo material que nem mesmo inclui, ainda, o nível vibratório, invisível e sutil. É o campo do indivisível, está além da quietude do mundo, como se a paz se fundisse com a verdade, o amor e o espírito. É o lugar da Unidade Plena. É a meta a ser alcançada na Iluminação. A ser vivida em outro tempo/ espaço. 
Uma proposta pedagógica com a compreensão da complexidade das dimensões humanas e que tenha como fundamento o amor, pode ser capaz de levar o educando a superar situações extremamente adversas, promovendo o apoio concreto às condições de vida, levando em conta todo o conjunto de necessidades da pessoa e também conectar esse educando ao do cosmos em que ela está integrada e até mesmo leva-lo a vivenciar a experiência interior de unicidade com todas as formas de vida.

Uma Educação na abordagem transdisciplinar baseada no amor pode concretizar em sua proposta uma práxis revolucionária e libertadora, capaz de promover a transformação social e o aperfeiçoamento interior do Ser Humano, atendendo aos aspectos materiais e espirituais que o conformam.

Esta é a missão desafiadora que o Relatório Delors $(2000)^{3}$ propõe para a educação no novo milênio: promover a integração desses níveis - o espiritual e o material, presentes na vida humana, única maneira de reverter o quadro sócio-econômico e ambiental que permeia o mundo atual.

Como já dizia Karl Marx (1978), em suas Teses sobre Feuerbach, toda vida social é essencialmente prática e não podemos nos limitar a interpretar o mundo, mas nos cabe transformá-lo.

Nas palavras de Marx

"Os filósofos se limitaram a interpretar o mundo diferentemente, cabe agora transformá-lo”.

"A coincidência da alteração das contingências (circunstância) com a atividade humana e a mudança de si próprio só pode ser captada e entendida racionalmente como praxis revolucionária." (1978:51).

Esse pensador que marcou os últimos dois séculos com suas idéias coloca um desafio para a educação apontando que para transformar o mundo é preciso transformar a si mesmo. Para mudar a mentalidade das novas gerações é preciso mudar a mentalidade do educador que tem essas gerações sob a sua orientação.

A educação tem hoje o desafio de introduzir, na referência cotidiana de mundo, as noções das áreas de ponta da ciência que, sob a ótica da física quântica, mostram um universo interativo. E

\footnotetext{
${ }^{3}$ Relatório para a UNESCO da Comissão Internacional sobre Educação para o Século XXI, publicado no livro Jacques Delors - Educação um Tesouro a Descobrir, S. Paulo. Cortez, 2000.
} 
o processo educacional deve ser capaz de proporcionar, na teoria e na prática, a compreensão e a vivência da unidade da vida.

A abordagem oferecida pela transdisciplinaridade aparece como uma resposta a essa necessidade histórica colocada para a educação de nosso tempo, enquanto apoio teórico e metodológico capaz de promover a reconexão entre ciência e cultura, entre as várias formas do saber, possibilitando a compreensão e a vivência na prática educativa que se transforma em práxis revolucionária fundamentada na noção de unicidade do mundo, e no o amor como princípio que sustenta a vida.

\section{REFERÊNCIAS BIBLIOGRÁFICAS}

ASSAGIOLI, Roberto. Psicossíntese. São Paulo: Cultrix, 1993.

D`AMBrosio, U. et al. Conhecimento, Cidadania e Meio Ambiente. Vol.3. São Paulo: Peirópolis, 1998.

ENGELS, Frederico. Sobre o papel do trabalho na transformação do macaco em homem in Obras Escolhidas, Vol.1. São Paulo.:ed. Sociais.1975.

CAPRA, Fritjof. O Ponto de Mutação. São Paulo: Cultrix, 1990.

HOEFFEL, J.eViana, R. at. Al. Conhecimento, Cidadania e Meio Ambiente. Vol 3. São Paulo: Peirópolis, 1998.

MATURANA, H. A Ontologia da Realidade. Belo Horizonte: UFMG, 1997.

MIGLIORI, R.et.al. Ética e Valores Humanos. Vol 1.São Paulo : Peirópolis, 1998.

MORAES, Maria Cândida. Paradigma Emergente na Educação. Campinas: Papirus, 2000.

SAI BABA, Sathya. Cultura y Espiritualidad .Buenos Aires: Errepar, 1996. 